\title{
Orléans - 18 rue Porte Saint-Jean
}

$\mathrm{n}^{\circ} 064531$

\section{Pascal Joyeux}

\section{(2) OpenEdition}

Journals

Édition électronique

URL : http://journals.openedition.org/adlfi/14346

ISSN : 2114-0502

Éditeur

Ministère de la culture

Référence électronique

Pascal Joyeux, «Orléans - 18 rue Porte Saint-Jean », ADLFI. Archéologie de la France - Informations [En ligne], Centre, mis en ligne le 20 mars 2015, consulté le 19 avril 2019. URL : http:// journals.openedition.org/adlfi/14346

Ce document a été généré automatiquement le 19 avril 2019

(c) Ministère de la Culture et de la Communication, CNRS 


\title{
Orléans - 18 rue Porte Saint-Jean
}

$n^{\circ} 064531$

\author{
Pascal Joyeux
}

Lien Atlas (MCC) :

http://atlas.patrimoines.culture.fr/atlas/trunk/index.php?

ap_theme=DOM_2.01.02\&ap_bbox=1.874;47.813;1.949;47.933

1 Le projet de construction d'un immeuble sur sous-sol au 18 rue Porte Saint-Jean à Orléans a entraîné la réalisation d'un diagnostic archéologique.

2 Ce projet est localisé dans un secteur peu connu. Les rares interventions ou découvertes laissent envisager une occupation antique de type artisanal.

3 Une tranchée a été réalisée dans l'espace exigu accessible lors de l'intervention. Elle a permis de mettre en évidence une fosse d'extraction de calcaire scellée par un niveau d'occupation. Ces éléments sont datés de la période gallo-romaine, sans qu'il soit possible d'être plus précis.

4 Postérieurement, les niveaux étudiés traduisent une mise en culture de l'espace. L'implantation d'une sépulture d'enfant au $\mathrm{XVII}^{\mathrm{e}}$ ou $\mathrm{XVIII}^{\mathrm{e}} \mathrm{s}$. met en évidence un changement dans la nature de l'occupation. Ce changement est peut-être à mettre en relation avec la construction, à proximité, de l'Hôpital Général à la période moderne. 
INDEX

operation Évaluation archéologique (EV)

Index chronologique : Gallo-romain, Temps Modernes

Mots-clés : fosse, sépulture

Index géographique : Centre, Loiret (45), Orléans 